\title{
Adding a Third Wh-phrase Does Not Increase the Acceptability of Object-initial Multiple-wh-questions
}

\author{
Evelina Fedorenko and Edward Gibson
}

Abstract. This paper quantitatively evaluates the empirical claim that adding a third $w h$-phrase to object-initial multiple-wh-questions increases their acceptability (e.g., Bolinger 1978, Kayne 1983) - a claim that posed a problem for accounts of the subject/object asymmetry in multiplewh-questions (e.g., Chomsky 1973, 1993; Lasnik \& Saito 1984; Pesetsky 1987, 2000; Richards 2001). Recently, Clifton et al. (2006) evaluated this claim using quantitative methods and failed to find support for it. However, a potential concern with Clifton et al.'s results was insufficient power to detect the effect of the third wh-phrase, possibly because of variance associated with several potential interpretations of multiple-wh-questions in null contexts. The goal of this paper is to extend the findings of Clifton et al. to cases where the critical sentences are presented in supportive contexts, so that the pair-list reading - the reading that has been argued to result in Superiority effects-is unambiguously supported. The results of the current study were similar to those of Clifton et al. and therefore provide further evidence against the claim that adding a third $w h$-phrase to object-initial multiple-wh-questions increases their acceptability.

\section{Introduction}

Kuno \& Robinson (1972) and Chomsky (1973) observed that there exists a subject/ object asymmetry in wh-extractions in multiple-wh-questions and in embedded multiple-wh-clauses in English. Specifically, whereas a wh-subject (e.g., who) can always appear in the clause-initial position in both matrix and embedded clauses (as shown in (1a) and (2a)), a wh-object (e.g., what) cannot appear clause-initially if the clause also contains a wh-subject (as shown in (1b) and (2b)). ${ }^{1}$

(1) a. Who bought what?

b. What did who buy?

(2) a. Mary wondered who bought what.

b. Mary wondered what who bought.

The inability of a $w h$-object to appear clause-initially in a multiple-wh-question or in an embedded multiple-wh-clause in the presence of a wh-subject in the clause was originally hypothesized by Chomsky to be due to the Superiority Condition. According to the Superiority Condition, an element $\mathrm{X}$ cannot move to a structural position above another element $\mathrm{Y}$ in cases where $\mathrm{Y}$ is superior to $\mathrm{X}$, where "superior" was defined in terms of a c-/m-command relationship between X and Y. The Superiority Condition therefore required noun phrases to appear in the order of

\footnotetext{
${ }^{1}$ Traditionally, (1b) and (2b) are preceded by an asterisk or a question mark to indicate that they are more syntactically complex than (1a) and (2a), respectively. We do not use this notation because it implies the existence of a categorical boundary between "grammatical" and "ungrammatical" structures, for which there is limited empirical evidence.
} 
their "superiority," with more superior items preceding less superior ones (subject NPs preceding direct object NPs, direct object NPs preceding indirect object NPs, etc.). A wh-subject (who) is superior to a wh-object (what). In structures (1b) and (2b) the wh-object is structurally above the wh-subject, thus violating the Superiority Condition and resulting in lower acceptability. A similar proposal was put forward by Lasnik \& Saito (1984), who argued that there is a constraint on possible transformations in wh-extractions, such that fronting of a wh-item is blocked when the clause contains a wh-item superior to it. According to some other accounts, Superiority effects result from a general preference for more economical derivations, where more economical derivations involve shorter movements or transformations. This idea applies to wh-extractions in multiple-wh-questions as follows: on the assumption that multiple $w h$-items compete for the clause-initial position, movement from the subject position is shorter, and thus more economical than movement from the object position, and is therefore preferred. An example of this class of accounts is the Minimal Link Condition (Chomsky 1993).

Since the original observation in the early 1970s, there have been numerous claims in the literature about potential variability in Superiority effects in English, as well as across languages (see, e.g., Sag et al. 2007 or Fedorenko \& Gibson 2008 for overviews). In this paper, we examine one source of variability that is claimed to exist in English. In particular, we evaluate the claim that adding a third wh-phrase to object-initial multiple-wh-questions increases their acceptability (e.g., Bolinger 1978, Kayne 1983).

Bolinger (1978), and later Kayne (1983), claimed that object-initial matrix or embedded multiple-wh-questions with a third wh-phrase added at the end (as shown in (3)) are more acceptable than the object-initial matrix or embedded multiplewh-questions without the third wh-element (as in (1b) and (2b)).

(3) a. What did who buy where?

b. Mary wondered what who bought where.

This claim, if true, is problematic for accounts of Superiority effects in English. For example, some existing accounts have tried to deal with this claim by postulating additional mechanisms or making additional assumptions (e.g., Kayne 1983; Pesetsky 1987, 2000; Richards 2001).

It is not clear, however, whether the claim is valid empirically. One potential concern regarding the original claim is that it was based on nonquantitative grammaticality judgments, elicited from a small number of speakers using a small number of examples. This methodology has received much criticism (e.g., Schütze 1996; Ferreira 2005; Wasow \& Arnold 2005; Gibson \& Fedorenko 2010, in press). Moreover, several cases now exist where quantitative investigations have revealed that the initial claims based on nonquantitative investigations have no empirical basis (e.g., Featherston 2005, Wasow \& Arnold 2005, Clifton et al. 2006, Gibson \& Fedorenko 2010). Particularly relevant to the current topic is the work of Clifton et al. (2006), who conducted a quantitative investigation of constructions with three wh-phrases and found no empirical support for the claim that a third wh-phrase 
increases the acceptability of object-initial multiple- $w$ h-questions. We summarize Clifton et al.'s findings below.

In experiment 1 , Clifton et al. compared the following three conditions:

(4) a. What can who do about it?

b. What can who do about it when?

c. What can you do about it, and when?

Condition (4a) is the standard two-wh-phrase question that violates the Superiority constraint. Condition (4b) is the critical condition where a third $w h$-phrase is added at the end. In half of the items the third wh-phrase was an adjunct (when, where), and in the other half it was an argument (to whom). This condition is claimed by Bolinger (1978) and Kayne (1983) to be more acceptable than condition (4a). Condition (4c) is a control condition, which does not involve a violation of the Superiority constraint and should therefore be rated highly acceptable. ${ }^{2}$

Clifton et al. used a speeded grammaticality judgment task. The results demonstrated that participants accepted the control condition (4c) much more frequently ( $83 \%$ of the time), than the two- $w h$-phrase condition ( $4 \mathrm{a})(25 \%$ of the time) or the three-wh-phrase condition (4b) ( $28 \%$ of the time), but the means for the twoand three-wh-phrase conditions did not differ. The pattern was the same for the items where the third $w h$-phrase was an argument and where it was an adjunct. There were also significant reaction time differences among the three conditions, but-as the authors acknowledge - these are hard to interpret because the conditions differ in terms of length.

To rule out the possibility that the lack of an effect of adding a third wh-phrase on the acceptability of object-initial multiple-wh-questions may be due to increased general complexity of these conditions (because they contain one additional wh-phrase), Clifton et al. conducted a second experiment. This experiment crossed the order of subject and object wh-phrases (subject-object/ object-subject) with the type of construction (two wh-phrases/three wh-phrases). ${ }^{3}$ This experiment was an off-line rating questionnaire where participants were asked to rate the acceptability of the structures on a scale from 1 to 5 . A main effect of the subject-object order was observed, such that the subject-object conditions were rated more highly than the object-subject conditions. Additionally, there was an interaction between the two factors, such that adding a third $w h$-phrase decreased the acceptability of multiple-wh-questions in the subject-object conditions, but it

${ }^{2}$ Clifton et al. also included a fourth condition (i), which-like condition (4b)-involved three wh-phrases but in which the third wh-phrase was separated by a comma and a conjunction.

(i) What can who do about it, and when?

Although potentially interesting to other hypotheses, this condition does not test Bolinger's and Kayne's original claim, and thus we will not discuss results involving this and related comparisons further here. See Clifton et al. 2006 for further discussion.

${ }^{3}$ Similar to experiment 1 , Clifton et al. also included a condition where the third wh-phrase was separated by a comma and a conjunction. As discussed in footnote 1, we will not discuss results relating to this comparison here because it does not test Bolinger's and Kayne's original claim. 
did not affect the acceptability of multiple-wh-questions in the object-subject conditions.

In summary, the results of the two experiments reported by Clifton et al. demonstrate that adding a third $w h$-phrase to object-initial multiple-wh-questions does not appear to increase their acceptability. This seems to be true regardless of whether the third wh-phrase is an argument or an adjunct.

The goal of the current study is to further evaluate the claim that adding a third $w h$-phrase to object-initial multiple-wh-questions increases their acceptability. In particular, the experiment was designed to extend the findings reported by Clifton et al. (2006) to materials presented in supportive contexts. Multiple-wh-questions have several potential interpretations (e.g., Bolinger 1978, Pesetsky 2000; see, e.g., Fedorenko \& Gibson 2008 for a recent summary), including (a) the pair-list $n$-tuplelist interpretation, ${ }^{4}$ (b) the echo-reprise interpretation, (c) the reference-reprise interpretation, and (d) the unique-referent interpretation. ${ }^{5}$ In the pair-list/n-tuple-list reading, the discourse consists of two or more sets of entities, which need to be paired or grouped. For example, the question What did who buy?/...wondered what who bought presupposes a set of buyers and a set of purchased objects, and the question requires information about the pairings between the two sets. For example, an appropriate answer to this question might be: John bought a book. Mary bought a $C D$. Susie bought a hat. The echo-reprise reading and the reference-reprise reading are quite similar to each other. In both of these readings, the discourse consists of two single entities (one corresponding to each of the wh-phrases), but only the identity of one of these entities (the subject) is asked about. The echo-reprise question often follows an object-extracted wh-question like What did [incomprehensible] buy?, and the wh-phrase in question (who) is marked with a rising intonation. The referencereprise question often follows an object-extracted wh-question like What did he buy? where the referent for the pronoun he is not clear from the context, and the wh-phrase in question (who) is marked with a falling intonation. An appropriate answer to either of these readings would constitute a single referent, like John. Finally, in the uniquereferent reading - similar to the echo-reprise and the reference-reprise readings - the discourse consists of two single entities (one corresponding to each of the wh-phrases), but only one of these entities (the object) is asked about. Sag et al. (2007) provide the following example:

(5) You're a complete mess.... What did who DO to you when you were a child?

In this example, the question seems to primarily ask about what was done in the presence of an unknown, but less relevant, identity of the agent.

Crucially, of the four readings, only the $n$-tuple-list reading appears to result in differential acceptability of subject- versus object-initial multiple-wh-questions

\footnotetext{
${ }^{4}$ The traditional name for this interpretation is the "pair-list interpretation." However, because it is possible to have more than two $w h$-phrases in a $w h$-question, we refer to this interpretation as the " $n$-tuplelist interpretation."

${ }^{5}$ We introduced this term in Fedorenko \& Gibson 2008, because there does not appear to be a term for this reading in the literature.
} 
(Pesetsky 2000). What makes the $n$-tuple-list reading different from the other three readings is that it asks about the identity of all of the wh-phrases, and about the pairings between two or more sets of referents for each of the wh-phrases. The answers to questions with this interpretation therefore require clauses consisting of entity-pairs, entity-triplets, and so forth, depending on the number of wh-phrases in the question. By contrast, in the echo-reprise, reference-reprise, and unique-referent readings, the question asks about the referent for only one of the wh-phrases in the presence of the unknown referent for the other wh-phrase. The answers to questions with these readings thus require a single entity.

Clifton et al. (2006) investigated multiple-wh-questions in null contexts. It is plausible that multiple- $w h$-questions receive the $n$-tuple-list interpretation in null contexts because this interpretation (a) requires a simpler discourse structure, and it has been demonstrated that in ambiguity resolution interpretations with simpler discourse structures are preferred (e.g., Crain \& Steedman 1985, Altmann \& Steedman 1988), and (b) does not require a special intonation. Thus, Clifton et al.'s materials are likely to have been interpreted in the $n$-tuple-list reading. The fact that a subject-object order contrast is observed further supports this hypothesis.

However, an evaluation of multiple-wh-questions in supportive contexts would strengthen Clifton et al.'s conclusions. As discussed earlier, multiple-wh-questions are ambiguous and only the $n$-tuple-list interpretation results in the subject/object asymmetry. Therefore, providing supportive contexts that unambiguously force the $n$-tuple-list reading would eliminate any uncertainty with regard to the correct interpretation. Furthermore, presenting the target constructions in supportive contexts reduces the variance associated with the individual participants' experiences with particular lexical items and with their world knowledge, therefore yielding higher statistical power (e.g., Gibson et al. 2007). If the effect of adding a third wh-phrase is real but small, then an increase in statistical power may enable us to detect this effect. Consequently, the current study examines multiple-wh-question constructions in supportive contexts.

\section{Experimental Methods}

\subsection{Participants}

Twenty-eight native speakers of English, who were students at MIT and members of the surrounding community, participated in the study. All participants were paid for their participation and were naive as to the purposes of the study.

\subsection{Design and Materials}

The experiment had a $2 \times 2$ design, crossing the order of subject and object wh-phrases (subject-object/object-subject) with the number of wh-phrases (two/ three). For the three-wh-phrase conditions, the third $w h$-phrase appeared last and varied across items being either an indirect object (13/28 items) or a temporal/spatial adjunct $(15 / 28$ items). 
The materials consisted of 28 sets of sentences appearing in supportive contexts. The materials were constructed based on the materials used in experiment 1 of Fedorenko \& Gibson 2008, but were modified and expanded because of the nature of the manipulations. The contexts introduced three sets of entities (in cases where the third wh-phrase was an indirect object) or two sets of entities and a set of times/ locations (in cases where the third wh-phrase was a temporal/spatial adjunct) that needed to be grouped. As discussed before, these contexts force the $n$-tuple-list interpretation of the multiple-wh-questions. The contexts were constructed such that they were felicitous for both two-wh-phrase-question conditions and three-wh-phrasequestion conditions. With the exception of a few items, different verbs had to be used for the two- and three-wh-phrase-question conditions. Two sample items (one with an indirect object as the third wh-phrase, and one with a temporal adjunct as the third wh-phrase) are shown in (6) and (7) (see the Appendix for the complete list of materials).

(6) Sample item (third wh-phrase-indirect object)

Context: It was a busy day at the fancy restaurant. All the tables were taken and several parties were waiting in line. At some point, because of the unusually high workload, several waiters messed up the orders.

a. Two wh-phrase conditions

The maitre d' tried to figure out \{who ordered what/what who ordered\}.

b. Three wh-phrase conditions

The maitre d' tried to figure out \{who served what to whom/what who served to whom $\}$.

(7) Sample item (third wh-phrase-temporal adjunct)

Context: Peter was moving to a new bigger apartment in the same building and he asked some of his friends to help him carry furniture and boxes on Sunday. He had five people helping him and it took them about five hours to move everything. When everything was moved, Peter noticed that one chair and a small bookshelf were nowhere to be found.

a. Two wh-phrase conditions

Peter and his friends were trying to remember \{who carried what/what who carried\}.

b. Three wh-phrase conditions

Peter and his friends were trying to remember \{who carried what when/what who carried when\}.

As can be seen in (6) and (7), another difference between the current experiment and Clifton et al.'s (2006) studies is that, whereas Clifton et al.'s materials involved multiple-wh-questions, our materials involve embedded multiplewh-clauses. There is no reason to expect a difference between main questions and embedded clauses with regard to the critical manipulation. However, generalizing the result across different construction types would further strengthen Clifton et al.'s conclusions. 
In addition to the 28 critical items, this experiment included 24 items from an unrelated experiment and 12 filler items. Both the unrelated-experiment items and the filler items were similar to the critical experimental materials in terms of their general structure, such that they consisted of a several sentences long context and a critical sentence following it. The critical sentence contained an embedded question in all the items. An example of a filler item is shown in (8). Four randomized lists were created following a Latin-Square design, such that each participant saw only one version of each item. Seven participants saw each list.

(8) Sample filler item

Context: The chemist was preparing to conduct a new experiment. He prepared all the necessary chemicals and beakers. His lab assistant was supposed to come soon and help him in carrying out the experiment. The chemist could not find the lab notebook with the notes on the experiment, which was conducted last week.

The chemist was trying to remember where the lab assistant kept the notebook.

\subsection{Procedure}

The task was an off-line rating questionnaire. Participants were given instructions explaining the task and were provided with several examples. In particular, participants were asked to rate how natural each sentence sounds on a scale from 1 (not at all natural) to 7 (very natural).

The experiment took approximately 35 minutes to complete.

\section{Experimental Results}

The means for the four conditions are presented in Figure 1 and in Table 1. A $2 \times 2$ ANOVA crossing the order of subject and object wh-phrases (subject-object/objectsubject) with the number of $w h$-phrases (two/three) revealed a highly significant main effect of $w h$-phrase order $\left(F_{1}(1,27)=132.3, M S E=173, p<.001 ; F_{2}(1,27)=226.0\right.$, $M S E=174, p<.001)$; a main effect of the number of $w h$-phrases, which was marginal in the items analysis $\left(F_{1}(1,27)=5.60, M S E=2.38, p<.05\right.$; $\left.F_{2}(1,27)=3.76, M S E=2.27, p=.063\right)$; and a significant interaction $\left(F_{1}(1,27)=\right.$ $\left.7.83, M S E=3.22, p<.01 ; F_{2}(1,27)=5.65, M S E=4.06, p<.05\right)$. First, the subjectobject conditions were rated more acceptable (6.22) than the object-subject conditions (3.74). Second, the two-wh-phrase conditions were rated more acceptable (5.13) than the three-wh-phrase conditions (4.84). And finally, whereas for the object-subject conditions there was no difference between the two- and three-wh-phrase conditions, for the subject-object conditions, the two-wh-phrase condition was rated more acceptable than the three-wh-phrase condition. The pattern of the results was similar for the items where the third wh-phrase was an argument and where the third wh-phrase was an adjunct. We additionally conducted a pair-wise comparison for the effect of the number of wh-phrases within the object-subject order and found no suggestion of an effect $\left(F_{\mathrm{s}}<1, p \mathrm{~s}>.7\right)$. 


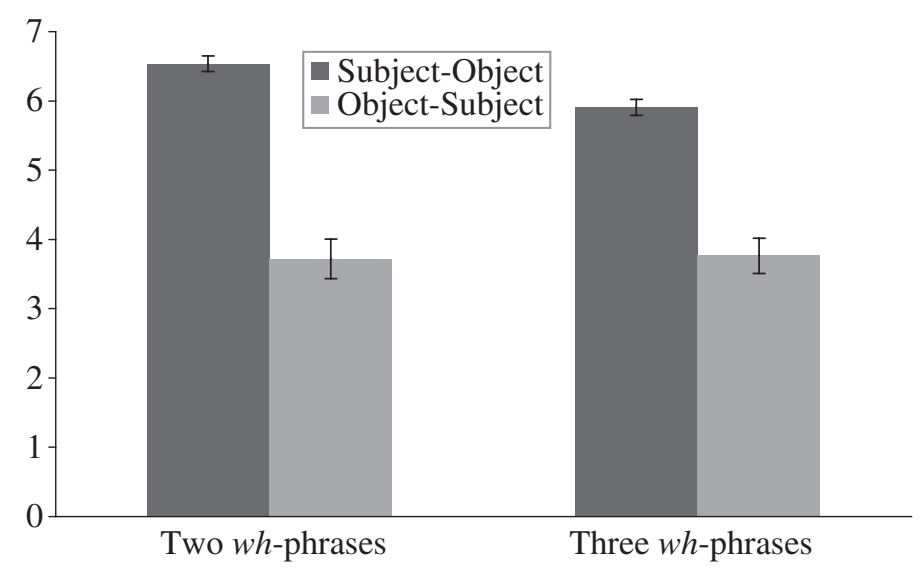

Figure 1: Acceptability ratings as a function of the wh-phrase order and the number of $w h$-phrases. The error bars indicate standard errors of the mean.

Table 1. Acceptability ratings as a function of the $w h$-phrase order and the number of $w h$-phrases (standard errors in parentheses).

\begin{tabular}{lll}
\hline Number of $\boldsymbol{w} \boldsymbol{h}$-phrases & Subject-Object & Object-Subject \\
\hline Two & $6.54(.11)$ & $3.72(.29)$ \\
Three & $5.91(.12)$ & $3.76(.25)$ \\
\hline
\end{tabular}

One could, in principle, make an argument that the observed interaction between the order of subject and object $w h$-phrases and the number of wh-phrases (similar to the interaction observed in Clifton et al.'s experiment 2) does in fact provide some evidence consistent with the original observations (e.g., Bolinger 1978, Kayne 1983). In particular, one could argue that because adding a third wh-phrase to object-initial multiple-wh-questions does not decrease their acceptability any further (as is the case for the subject-initial multiple-wh-questions), the resulting intuitive judgment may be that of increased acceptability if participants evaluate object-initial multiplewh-questions in relation to their subject-initial counterparts. In this case, because the difference between the subject- and the object-initial conditions is smaller for the three-wh-phrase conditions than for the two-wh-phrase conditions, the object-initial three-wh-phrase condition may be intuitively perceived as more acceptable than the object-initial two-wh-phrase condition. However, the initial claims did not invoke judgments about object-initial constructions relative to their subject-initial counterparts. Rather, they involved the direct contrast between the two object-initial constructions: that with two wh-phrases and that with three $w h$-phrases. As a result, this kind of reasoning is far-fetched, requiring additional assumptions. See also Clifton et al.'s arguments against this reasoning (2006:60-61). 


\section{Summary and Conclusions}

This experiment was designed to test the claim that the presence of a third wh-phrase in object-initial multiple-wh-questions increases their acceptability (e.g., Bolinger 1978, Kayne 1983). Contrary to the claim, the acceptability of the three-wh objectinitial condition was statistically indistinguishable from the two-wh object-initial condition. This work extends Clifton et al.'s (2006) findings. In particular, it shows that the pattern of the results is the same when the critical sentences are presented in supportive contexts. Even with the greater statistical power of supportive contexts, no suggestion of an effect was present. One additional implication that this work has, similar to Clifton et al.'s experiments, is that claims in the linguistics literature that involve complex intuitive judgments need to be evaluated quantitatively: intuitive grammaticality judgments elicited from a small number of (often biased) speakers and using a small number of examples are not a reliable source of empirical data (Featherston 2005; Wasow \& Arnold 2005; Clifton et al. 2006; Gibson \& Fedorenko 2010 , in press).

\section{References}

Altmann, G. T. M. \& M. Steedman. 1988. Interaction with context during human sentence processing. Cognition 30:191-238.

Bolinger, D. 1978. Asking more than one thing at a time. In Questions, ed. H. Hiz, 97-106. Dordrecht: Reidel.

Chomsky, N. 1973. Conditions on transformations. In A festschrift for Morris Halle, ed. S. Anderson \& P. Kiparsky, 232-286. New York: Holt, Rinehart \& Winston.

Chomsky, N. 1993. A Minimalist Program for linguistic theory. In The view from Building 20, ed. K. Hale \& S. J. Keyser, 1-52. Cambridge, MA: MIT Press.

Clifton, C. Jr, G. Fanselow \& L. Frazier. 2006. Amnestying superiority violations: Processing multiple questions. Linguistic Inquiry 37:51-68.

Crain, S. \& M. Steedman. 1985. On not being led up the garden path: The use of context by the psychological syntax processor. In Natural language parsing: Psychological, computational, and theoretical perspectives, ed. D. R. Dowty, L. Kartunnen \& A. Zwicky, 320-358. Cambridge: Cambridge University Press.

Featherston, S. 2005. Universals and grammaticality: Wh-constraints in German and English. Linguistics 43:667-711.

Fedorenko, E. \& E. Gibson. 2008. Syntactic parallelism as an account of superiority effects: Empirical investigations in English and Russian. Ms., MIT, Cambridge, MA.

Ferreira, F. 2005. Psycholinguistics, formal grammars, and cognitive science. The Linguistic Review 22:365-380.

Gibson, E. \& E. Fedorenko. 2010. The need for quantitative methods in syntax. Ms., MIT, Cambridge, MA.

Gibson, E. \& E. Fedorenko. In press. Weak quantitative standards in linguistics research. Trends in Cognitive Sciences.

Gibson, E., E. Fedorenko \& T. Ishizhuka. 2007. The role of discourse-level predictability in sentence comprehension. Paper presented at CUNY Conference on Human Sentence Processing, San Diego, CA (March).

Kayne, R. 1983. Connectedness. Linguistic Inquiry 14:223-249.

Kuno, S. \& J. Robinson. 1972. Multiple wh-questions. Linguistic Inquiry 3:463-487.

Lasnik, H. \& M. Saito. 1984. On the nature of proper government. Linguistic Inquiry 15:235289. 
Pesetsky, D. 1987. Wh-in-situ: Movement and unselective binding. In The representation of (in)definiteness, ed. E. Reuland \& A. ter Meulen, 98-129. Cambridge, MA: MIT Press.

Pesetsky, D. 2000. Phrasal movement and its kin. Cambridge, MA: MIT Press.

Richards, N. 2001. Movement in language. Oxford: Oxford University Press.

Sag, I., P. Hofmeister, I. Arnon, N. Snider \& F. Jaeger. 2007. Processing accounts for superiority effects. Ms., Stanford University, Stanford, CA.

Schütze, C. 1996. The empirical base of linguistics: Grammaticality judgments and linguistic methodology. Chicago: University of Chicago Press.

Wasow, T. \& J. Arnold. 2005. Intuitions in linguistic argumentation. Lingua 115:14811496.

Evelina Fedorenko

Massachusetts Institute of Technology Department of Brain and Cognitive Sciences

43 Vassar St., 46-3037F

Cambridge, MA 02139

USA

evelina9@mit.edu

Edward Gibson

Massachusetts Institute of Technology

Department of Brain and Cognitive Sciences

43 Vassar St., 46-3035

Cambridge, MA 02139

USA

egibson@mit.edu

\section{Appendix: Materials}

The contexts and the verbs used for the two-wh-phrase conditions and the threewh-phrase conditions are shown here for each of the 28 items (only one verb is provided for items where the same verb was used for all four conditions). The four versions of the critical sentence can be generated as exemplified in item 1 below. Items 1-3, 5-8, 10, and 13-18 used an indirect object in the three-wh-phrase conditions; the remaining items used a temporal/spatial adjunct.

1. It was a busy day at the fancy restaurant. All the tables were taken and several parties were waiting in line. At some point, because of the unusually high workload, several waiters messed up the orders. [ordered/served]
a. The maitre d' tried to figure out who ordered what.
b. The maitre d' tried to figure out what who ordered.
c. The maitre d' tried to figure out who served what to whom.
d. The maitre d' tried to figure out what who served to whom. 
2. At Christmas the employees of the company played a game of Secret Santa. Each employee brought a wrapped gift addressed to another employee and secretly placed it under the Christmas tree. At the party, everybody unwrapped their gifts. [brought/gave]

3. Several new employees were hired last week at the medical devices factory. The job involved receiving new orders submitted through the company's website and mailing the ordered products to the customers. The new employees were not trained properly, and so they did not keep track of all the orders that came in and that they mailed out. [ordered/mailed]

4. A big conference for the American Cancer Society was held at the Marriott Hotel. As it often happens, many of the attendees lost various items by leaving them in the conference hall or in the corridors during the breaks. Luckily, the hotel had a lost-and-found service, which kept all the items. During the last day of the conference several people were standing in line at the lost-and-found office trying to locate their misplaced belongings. [was missing/left]

5. A big sale event was happening at the car dealership last week. Several salesmen were helping many interested customers. In the afternoon several cars got sold. [bought/sold]

6. A non-profit debt consolidation firm was holding a seminar for people who had many debts to help them get control of their finances. At the first meeting, everybody introduced themselves. [owed]

7. At the university, several professors and a group of graduate students were organizing a workshop. A professor from the physics department was in charge of the schedule. He had to invite some speakers from various universities, and he also had to ask the other professors to assign some papers to be presented by graduate students. [would present/should assign]

8. For Christmas, the parents of children attending kindergarten were planning a party where one of the fathers would dress as Santa Claus and would give out the presents to the kids. All the parents told him about the presents their children wanted and about the kinds of presents they promised the children Santa Claus would bring. [wanted/promised]

9. It was the end of the semester at the culinary school and the final grades were due soon. In the French cuisine class the way the instructor was evaluating students' work was by having each student bring a French dish they prepared on a particular date. This way, at the beginning of each class there was a little food tasting session where the instructor and the students in the class evaluated the dish on several dimensions. The instructor didn't take careful notes throughout the semester, hoping that his memory would serve him well, but when the time came to assign the grades, he had a hard time. [cooked]

10. The owner of a bicycle rental shop hired three assistants for the summer, because he was having an unusually high number of customers. On the first day of work, the assistants rented out many bikes, but they didn't keep careful records of the transactions. [rented] 
11. Some architecture students at the local school of design were taking a tour of the city. They visited many different areas and saw many interesting buildings designed by famous architects. [designed]

12. Each student in a psychology class had to make a short presentation at some point in the semester. The professor was sick for a few weeks, and another professor was substituting for him. However, the substitute professor forgot to write down the presentations that took place in each class. [presented]

13. At the timeshare sales office there were several interested customers. There were several sales associates giving presentations about the condos. At the end of the presentations, the sales associates were supposed to show each customer one of the available condos. [would show]

14. Some kids in a preschool class were learning to read out loud. The previous day, the teacher broke the kids down into pairs, gave each pair a book, and then had one of the kids read to the other from the book. Today, the teacher wanted to reverse the roles. [read]

15. In the suburbs of Boston a lot of new buildings were being built by different construction companies. Some of the buildings were large apartment complexes built for various real estate companies. Other buildings were supposed to house various administrative offices. Yet other buildings were built for commercial purposes for various local and international companies. The city administration recently lost some of the records. [built]

16. The students in the 6th grade went on a day trip to the New England Aquarium. At the end of the tour everybody rushed to the gift shop to buy some souvenirs. Some of the students didn't bring any money and had to borrow from their friends. However, later, some of the kids were confused about who borrowed money from them or from whom they borrowed money. [borrowed/lent]

17. Several doctors were working today in the cardiology department. It was a busy day and each doctor saw many patients. The doctors prescribed different medications to different patients. However, the secretary was sloppy and got confused about all the different prescriptions. [prescribed]

18. A group of local charities received many donations during a recent fund drive. Some people donated money, others brought in food, clothes, books, and toys for children. The administrators of the charities sat down to write thank-you notes for the donors, but they realized that some donations didn't have the names of donors or receiving charities associated with them. [donated]

19. A graduate student was writing a research paper for a class in psychology. In the introduction she wanted to summarize some important findings in the area of visual processing. She could recall most of the important results but often didn't know the researchers and the dates of the studies. [demonstrated]

20. An engineering company organized fun events for the employees every few months. At the end of each event there was a prize drawing. Prizes often included gift certificates for local restaurants, music CDs, and movie or theater tickets. This month there were two such events to celebrate the company's recent patent that got approved. However, the administrator who was responsible for 
distributing the prizes was away for the last few weeks, and when she came back and wanted to distribute the prizes from the last two events, she couldn't locate the forms, which listed the winners and the prizes. [won]

21. The undergraduate student advisor in the Biology department was keeping track of which classes the biology majors took each semester. The department recently relocated to a new building and some of the files got lost. [took]

22. Peter was moving to a new bigger apartment in the same building and he asked some of his friends to help him carry furniture and boxes on Sunday. He had five people helping him and it took them about five hours to move everything. When everything was moved, Peter noticed that one chair and a small bookshelf were nowhere to be found. [carried]

23. The annual neuroscience conference had an online abstract submission form. Everything was working smoothly until the very last day when due to a large number of people using the website, something went wrong and for several abstracts the information about the authors and also the time-stamp of the submission got lost. [submitted]

24. A marketing research company was conducting an analysis of how effective event sponsorship is. Specifically, they were interested in how much the sponsoring of sports events boosts the companies' profits. The intern who was hired to work on this project was told to compile a list of important sports events in the last five years and the names of the sponsors. [sponsored]

25. Grandmother took little Timmy to the Science museum. One hall contained a variety of inventions by various engineers from the last three centuries. Little Timmy was four and couldn't read very well yet. [invented]

26. Andrew had a literature test today at school. He had to know about the life of famous writers and about their literary works. During the test he got totally confused. [wrote]

27. William was the host of the talent show The U.S. Idol. The contestants came from all over the country to try out for the show. One of the contest rules was that the contestants did not know what they were going to sing until the very last moment and also the order in which they would have to perform. [would sing]

28. Christina loved the impressionists and knew their art works very well. Sometimes, she played a game with her Mom where her Mom showed her postcards with the works of the impressionists and asked questions about them. [painted] 